\title{
ChemComm
}

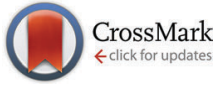

Cite this: Chem. Commun., 2016, 52,8585

Received 15th April 2016,

Accepted 14th June 2016

DOI: $10.1039 / \mathrm{c} 6 \mathrm{cc} 03190 \mathrm{k}$

www.rsc.org/chemcomm

\section{Design and synthesis of squaramide-based MOFs as efficient MOF-supported hydrogen-bonding organocatalysts $\dagger$}

\author{
Xiaoping Zhang, $\ddagger^{\mathrm{ab}}$ Zhenjie Zhang, $\ddagger^{\mathrm{a}}$ Jake Boissonnault ${ }^{\mathrm{a}}$ and Seth M. Cohen ${ }^{\mathrm{a}}$
}

\begin{abstract}
Herein, we utilize a new, squaramide-based ligand, combined with a postsynthetic exchange (PSE) synthetic approach to prepare a series of $\mathrm{Cu}(\mathrm{II})$-squaramide MOFs that are active catalysts for the Friedel-Crafts reaction.
\end{abstract}

Among various organocatalysts, those based on the thiourea core are broadly utilized in the field of H-bond donor catalysis. ${ }^{1}$ Recently, bifunctional squaramide moieties have emerged as powerful hydrogen-bonding groups for Lewis acid catalysis. ${ }^{2-8}$ Squaramides are four-membered ring systems, which are derived from squaric acid and possess hydrogen-bond accepting and donating functionality through their carbonyl and $\mathrm{N}-\mathrm{H}$ groups, respectively. The squaramide functionality possesses features such as ditopic binding, structural rigidity, high $\mathrm{N}-\mathrm{H}$ acidity, and ease of preparation. ${ }^{9}$ Squaramide compounds have been shown to be competent for biomimetic transport, ${ }^{5,10,11}$ molecular recognition, ${ }^{12}$ ion sensing, ${ }^{13,14}$ and organocatalysis. ${ }^{15,16}$ The high propensity for hydrogen-bonding is driven via a concomitant increase in aromaticity on the squaramide ring. ${ }^{17}$ Although the increased acidity of squaramides can be useful in hydrogen-bond donating organocatalysis, the strong hydrogen-bonding also drives self-association/ aggregation of squaramides that impedes catalysis. ${ }^{18}$ To prevent self-association and enhance the catalytic performance of squaramides, one strategy is to immobilize these groups within porous materials such as metal-organic frameworks (MOFs). ${ }^{19,20}$

MOFs are a class of porous, crystalline materials composed of inorganic nodes and organic linkers. They have uniform 3-dimensional structures of high surface area, large pore sizes,

\footnotetext{
${ }^{a}$ Department of Chemistry and Biochemistry, University of California, San Diego, La Jolla, California 92093, USA. E-mail: scohen@ucsd.edu

${ }^{b}$ Department of Chemistry, Key Laboratory of Advanced Energy Materials Chemistry (MOE), Collaborative Innovation Center of Chemical Science and Engineering, Nankai University, Tianjin 300071, P. R. China

$\dagger$ Electronic supplementary information (ESI) available: Experimental procedures, FTIR, TGA, PXRD, ${ }^{1} \mathrm{H}$ NMR, and crystallographic data. CCDC 1472314 and 1472315. For ESI and crystallographic data in CIF or other electronic format see DOI: 10.1039/ c6cc03190k

\# These authors contributed equally.
}

low density, and have potential applications in gas sorption, ${ }^{21,22}$ molecular recognition, ${ }^{23}$ proton conductivity, ${ }^{24}$ and organocatalysis. ${ }^{25-29}$ Along with their modular synthesis and tunable porosity, MOFs constitute attractive candidates as platforms for heterogeneous catalysis.

To incorporate squaramide catalysts into MOFs, a feasible design approach is to employ squaramide compounds as ligand struts for MOFs. Hupp, Farha, and Mirkin developed a mixedligand MOF catalyst, UiO-67-Squar/bpdc, ${ }^{20}$ which was constructed using a combination of unfunctionalized and squaramideappended biphenyl dicarboxylate (bpdc) ligands. In this system, the squaramide group was attached as a 'dangling' substituent off of the bpdc ligand framework. The percentage of squaramide ligand incorporation was varied from $0-100 \%$. The authors reported that MOFs with $100 \%$ squaramide ligand incorporation showed low catalytic activity, similar to those MOFs with $100 \%$ unfunctionalized bpdc ligand (e.g. no catalytic sites). MOFs with $50 \%$ squaramide ligand exhibited the highest catalytic activity, which was attributed to an optimal balance of catalytic sites and sufficient retention of MOF porosity. Herein, an alternative approach presented for squaramide-based MOF catalysts is described. A new squaramide ligand with four carboxylate ligating groups $\left(5,5^{\prime}\right.$ (3,4-dioxocylcobut-1-ene-1,2-diyl)bis(azanediyl)diisophthalic acid, $\mathrm{H}_{4} \mathrm{dbda}$, Fig. 1) has been designed and synthesized. Using $\mathrm{H}_{4} \mathrm{dbda}$, we developed a stable $\mathrm{Cu}-\mathrm{MOF}$, $\left[\mathrm{Cu}_{2}(\mathrm{dbda})\left(\mathrm{CH}_{3} \mathrm{OH}\right)_{2}\right]$ (Cu(dbda)), through a postsynthetic exchange (PSE) reaction from its $\mathrm{Zn}$ (II) analogue, $\left[\mathrm{Zn}_{2}(\mathrm{dbda})\left(\mathrm{H}_{2} \mathrm{O}\right)_{2}\right]$ ( $\mathbf{Z n}$ (dbda)). The Friedel-Crafts reaction, a prototypical reaction for hydrogenbonding organocatalyst, ${ }^{30-34}$ was selected to evaluate the catalytic performance of these MOFs (Fig. 1). Cu(dbda) demonstrated high catalytic efficiency for the Friedel-Crafts reaction between indole and substituted $\beta$-nitrostyrenes while $\mathbf{Z n}(\mathbf{d b d a})$ was not a catalyst due to its poor stability. The $\mathbf{C u}(\mathbf{d b d a})$ system allows for $100 \%$ incorporation of the $\mathrm{H}_{4} \mathrm{dbda}$ squaramide ligand without a significant loss of MOF porosity.

The $\mathrm{H}_{4} \mathrm{dbda}$ ligand was synthesized using a modified literature procedure. ${ }^{35}$ Both ${ }^{1} \mathrm{H}$ NMR and MS data confirmed the composition of the ligand (Fig. S1 and S2, ESI $\dagger$ ). Combining $\mathrm{H}_{4} \mathrm{dbda}$ and 
(a)

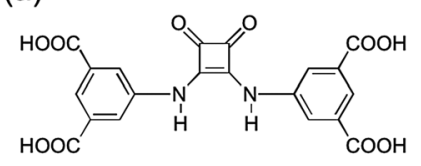

(b)

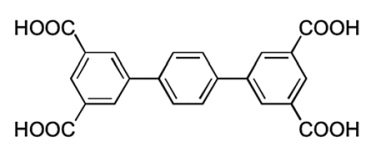

(c)

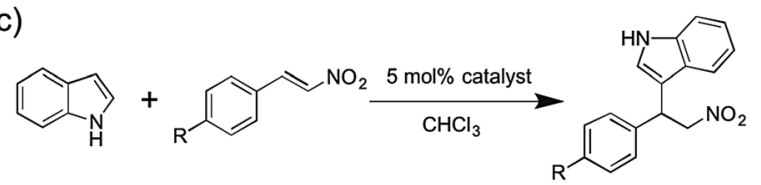

Fig. 1 (a) Structure of the $\mathrm{H}_{4}$ dbda ligand. (b) Structure of $\mathrm{H}_{4}$ tptc ligand. (c) Friedel-Crafts reaction between indole and substituted $\beta$-nitrostyrenes.

$\mathrm{Zn}\left(\mathrm{NO}_{3}\right)_{2}$ in a mixture of $\mathrm{DMF}$ and $\mathrm{EtOH}$ at $80{ }^{\circ} \mathrm{C}$ for $24 \mathrm{~h}$ afforded pale-yellow crystals of $\mathbf{Z n}(\mathbf{d b d a})$. Single-crystal X-ray diffraction (XRD) structure determination revealed that $\mathbf{Z n ( d b d a ) ~ c r y s t a l l i z e d ~}$ in the $R \overline{3} m$ space group with unit cell parameters $a=b=18.8687(9) \AA$, $c=38.3555(17) \AA, \alpha=\beta=90^{\circ}, \gamma=120^{\circ}$ (Table S1, ESI $\dagger$ ). As shown in Fig. 2, $\mathbf{Z n}\left(\right.$ dbda) is built by $\left[\mathrm{Zn}_{2}(\mathrm{COO})_{4}\right]$ paddlewheel secondary building units (SBUs). The 1,3-benzenedicarboxylate (1,3-bdc) moieties in $\mathrm{dbda}^{4-}$ are linked by $\left[\mathrm{Zn}_{2}(\mathrm{COO})_{4}\right]$ SBUs to form a 2-dimensional Kagomé lattice that are connected via the squaramide core to form an overall 3-dimensional framework with nbo topology (Fig. S3 and S4, ESI $\dagger$ ). There are large channels with approximate dimensions of $13 \times 5 \AA$ Along the crystallographic $c$-axis. $\mathrm{N}_{2}$ sorption of $\mathbf{Z n ( d b d a )}$ showed essentially no uptake (Fig. 3), which is attributed to a loss of $\mathbf{Z n}$ (dbda) crystallinity upon thermal activation $\left(60{ }^{\circ} \mathrm{C}, 10 \mathrm{~h}\right)$ as evidenced by powder X-ray diffraction (PXRD, Fig. S5, ESI $\dagger$ ). Zn(dbda) was found to be stable in common organic solvents such as $\mathrm{CHCl}_{3}$ for $24 \mathrm{~h}$ at room temperature, but not stable in water (Fig. S6 and S7, ESI $\dagger$ ). Despite these stability limitations, the catalytic performance of $\mathbf{Z n}(\mathbf{d b d a})$ in the Friedel-Crafts reaction was examined. Indole $(0.15 \mathrm{mmol})$ and $\beta$-nitrostyrene $(0.1 \mathrm{mmol})$ were chosen as test substrates, and the reaction was performed at $50{ }^{\circ} \mathrm{C}$ in $\mathrm{CHCl}_{3}$ with $5 \mathrm{~mol} \%$ loading of the $\mathbf{Z n ( d b d a )}$ catalyst (based on an empirical formula of $\left.\mathrm{Zn}_{4}(\mathrm{dbda})_{2}\left(\mathrm{H}_{2} \mathrm{O}\right)_{4}\right)$; however, no products were observed after $24 \mathrm{~h}$ (Fig. S8, ESI $\dagger$ ). PXRD of Zn(dbda) after $24 \mathrm{~h}$ revealed that the MOF had lost crystallinity under the reaction conditions (Fig. S9, ESI $\dagger$ ).

Literature reports suggest that $\left[\mathrm{Zn}_{2}(\mathrm{COO})_{4}\right]$ SBUs may possess low chemical stability. ${ }^{36}$ However, there are reports of $\mathrm{Zn}$ (II)

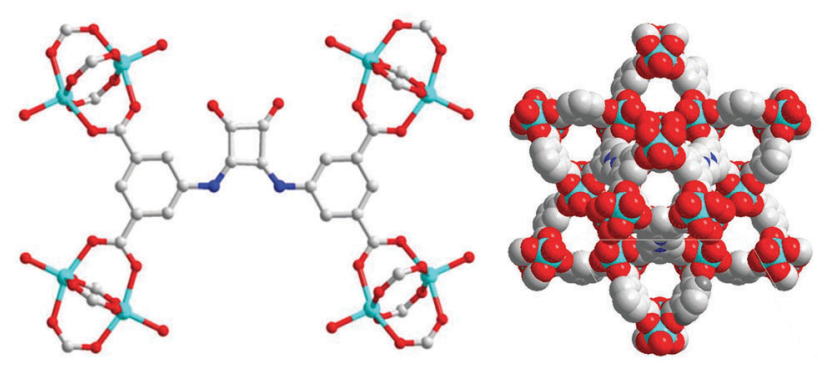

Fig. 2 Coordination environment of Zn(dbda) (left). Packing of Zn(dbda) along the crystallographic c-axis (right). Color code: O, red; N, blue; Zn, cyan; C, gray.

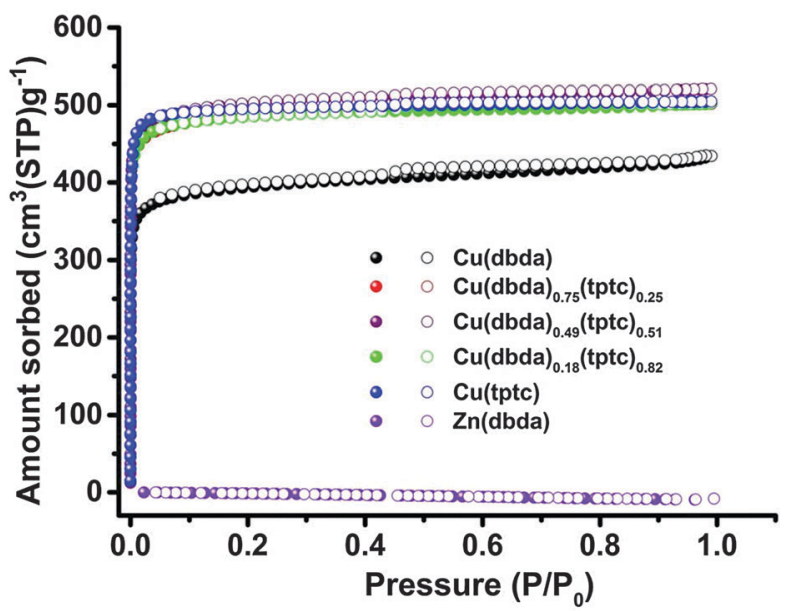

Fig. $3 \mathrm{~N}_{2}$ gas sorption of $\mathbf{C u}(\mathbf{d b d a})_{\boldsymbol{x}}(\mathbf{t p t c})_{1-\boldsymbol{x}}(x=1,0.75,0.49,0.18,0)$. Adsorption and desorption branches are shown with filled and empty symbols, respectively.

SBUs that can undergo PSE with $\mathrm{Cu}(\mathrm{II})$ cations and the resulting $\mathrm{Cu}(\mathrm{II})$-based SBUs showing greater chemical stability. ${ }^{37}$ PSE of $\mathbf{Z n ( d b d a ) ~ w i t h ~} \mathrm{Cu}\left(\mathrm{NO}_{3}\right)_{2}$ produced a new compound $\mathbf{C u}(\mathbf{d b d a})$ (Fig. S10, ESI $\dagger$ ); attempts to prepare $\mathbf{C u ( d b d a ) ~ d i r e c t l y ~ f r o m ~}$ $\mathrm{H}_{4} \mathrm{dbda}$ and various $\mathrm{Cu}$ salts were unsuccessful under a variety of reaction conditions. Both EDX $(\sim 99 \% \mathrm{Cu})$ and ICP-OES ( $\sim 99 \% \mathrm{Cu}$ ) showed that the $\mathrm{Zn}(\mathrm{II})$ ions were essentially completely replaced by $\mathrm{Cu}$ (II) by this PSE process (Fig. S11 and Table S2, ESI $\dagger$ ). $\mathrm{XRD}$ of $\mathbf{C u}(\mathbf{d b d a})$ revealed that $\mathbf{C u}(\mathbf{d b d a})$ exhibited the same structure as $\mathbf{Z n ( d b d a ) , ~ w i t h ~ o n l y ~ s l i g h t ~ d i f f e r e n c e s ~ i n ~ c e l l ~}$ parameters: $a=b=18.2623(6) \AA \circ, c=39.6543(13) \AA$. Cu(dbda) possesses a slightly smaller unit cell $\left(V=11453.3(7) \AA^{3}\right)$ than Zn(dbda) $\left(V=11826.1(10) \AA^{3}\right)$ (Table S3, ESI $\dagger$ ) due to the shorter $\mathrm{Cu}-\mathrm{O}$ bonds. For $\mathbf{Z n}(\mathbf{d b d a})$, the average distance of $\mathrm{Zn}-\mathrm{O}$ (carboxylate) bonds is $2.036 \AA$, while for $\mathbf{C u}(\mathbf{d b d a})$, the average $\mathrm{Cu}-\mathrm{O}$ (carboxylate) distance is $1.947 \AA$. Moreover, the metalmetal distance in the paddlewheel SBUs decreased from $2.999 \AA$ (Zn-Zn) to $2.629 \AA$ (Cu-Cu). The permanent porosity of $\mathbf{C u}(\mathbf{d b d a})$ was measured by $\mathrm{N}_{2}$ absorption at $77 \mathrm{~K}$, which showed a typical type I isotherm, ${ }^{38}$ giving a BET surface area of $1516 \pm 66 \mathrm{~m}^{2} \mathrm{~g}^{-1}$ and a total pore volume of $0.662 \mathrm{~cm}^{3} \mathrm{~g}^{-1}$ (Fig. 3). The PXRD pattern of $\mathbf{C u}(\mathbf{d b d a})$ remains intact upon immersion in organic solvents for $90 \mathrm{~h}$, suggesting improved stability consistent with the gas sorption data; however, $\mathbf{C u ( d b d a ) ~ w a s ~ u n s t a b l e ~ i n ~ w a t e r ~}$ (Fig. S12 and S13, ESI $\dagger$ ).

The model reaction between indole $(0.15 \mathrm{mmol})$ and $\beta$-nitrostyrene $(0.10 \mathrm{mmol}$, Fig. 1) was examined with $5 \mathrm{~mol} \%$ loading of $\mathbf{C u}$ (dbda) (based on an empirical formula of $\mathrm{Cu}_{4}(\mathrm{dbda})_{2}$ $\left.\left(\mathrm{CH}_{3} \mathrm{OH}\right)_{4}\right)$ as a catalyst. Under identical conditions to those reported for UiO-67-Squar/bpdc $\left(\mathrm{CD}_{2} \mathrm{Cl}_{2}, 25{ }^{\circ} \mathrm{C}, 24 \mathrm{~h}\right), \mathrm{Cu}(\mathrm{dbda})$ gave a yield of only $32 \%$, compared to $78 \%$ for UiO-67-Squar/ bpdc. ${ }^{20}$ Therefore, reaction conditions were optimized for $\mathbf{C u}(\mathbf{d b d a})$ including the use of different solvents (toluene, $\mathrm{CH}_{3} \mathrm{CN}, \mathrm{CHCl}_{3}$ ) and temperatures $\left(25,35\right.$, and $50{ }^{\circ} \mathrm{C}$ ) (Table S4 and Fig. S14, ESI $\dagger$ ). It was found that $\mathrm{CHCl}_{3}$ gave the best results, and activity could be increased with increasing temperature from $\sim 60 \%$ $\left(25{ }^{\circ} \mathrm{C}\right)$, to $\sim 78 \%\left(35{ }^{\circ} \mathrm{C}\right)$, to $>99 \%\left(50{ }^{\circ} \mathrm{C}\right)$. Control reactions 
either without catalyst or with free $\mathrm{H}_{4} \mathrm{dbda}$ ligand (not as part of a MOF) were also performed under the same optimized reaction conditions. Without catalyst, no product was observed. The catalytic activity of free $\mathrm{H}_{4} \mathrm{dbda}$ was much lower than the MOF, giving a yield of only 33\% after $24 \mathrm{~h}$ (Fig. S15, ESI $\dagger$ ). The improved activity of $\mathbf{C u}(\mathbf{d b d a})$ suggests that the MOF prevents squaramide self-aggregation, which likely causes the sluggish activity of the free $\mathrm{H}_{4} \mathrm{dbda}$ ligand. A time-dependent study was performed from $30 \mathrm{~min}$ to $24 \mathrm{~h}$ (Fig. S16, ESI $\dagger$ ). The conversion of $\beta$-nitrostyrene was $\sim 60 \%$ (turnover frequency, TOF $=3.0 \times$ $\left.10^{-3} \mathrm{~s}^{-1}\right)$ after $1 \mathrm{~h}$, with $95 \%$ conversion after $8 \mathrm{~h}(\mathrm{TOF}=6.6 \times$ $10^{-4} \mathrm{~s}^{-1}$ ), and complete consumption of the starting material after $24 \mathrm{~h}$.

An advantage of heterogeneous catalysts is reusability, which was also investigated for $\mathbf{C u ( d b d a ) . ~ O n l y ~ a ~ s m a l l ~ d e c r e a s e ~ i n ~}$ activity (from $>99 \%$ to $\sim 96 \%$ ) was observed after 5 runs (Fig. S17, $\mathrm{ESI} \dagger)$. Characterization of $\mathbf{C u}(\mathbf{d b d a})$ after the 5 th run showed the catalyst retained its crystallinity, with the PXRD pattern of the recycled $\mathbf{C u}(\mathbf{d b d a})$ in good agreement with the calculated patterns (Fig. S18, ESI $\dagger$ ). A test was performed to confirm the heterogeneity of the catalysts (and rule out soluble species) by removing the MOF catalyst by filtration after $30 \mathrm{~min}$ (at which time the yield was $\sim 22 \%$ ). The filtrate was then re-analyzed after a total of $24 \mathrm{~h}$ showing no formation of new product and indicating that the catalyst is heterogeneous and there is no leaching of a catalytic species into solution (Fig. S16, ESI $\dagger$ ). ${ }^{20}$ The substrate scope for various substituted-nitrostyrene derivatives was also examined to assess the utility of $\mathbf{C u}$ (dbda) (Fig. S19, ESI $\dagger$ ). Good to excellent yields, ranging from $\sim 61 \%$ for 4 -nitro- $\beta$-nitrostyrene (poor solubility in $\mathrm{CHCl}_{3}$ ) to $97 \%$ for 4 -chloro- $\beta$-nitrostyrene, were obtained (Table 1). Overall, these results show that $\mathbf{C u ( d b d a )}$ is an efficient, recyclable, heterogeneous catalyst for the Friedel-Crafts reaction.

To further investigate the catalytic activity of $\mathbf{C u}(\mathbf{d b d a})$, a series of isostructural MOF catalysts, $\left[\mathrm{Cu}_{2}(\mathrm{dbda})_{x}(\mathrm{tptc})_{1-x}\left(\mathrm{CH}_{3} \mathrm{OH}\right)_{2}\right]$ $\left(\mathbf{C u}(\mathbf{d b d a})_{x}(\mathbf{t p t c})_{1-x}, x=0.75,0.49,0.18,0 ; \mathrm{H}_{4}\right.$ tptc $=p$-terphenyl$3,5,3^{\prime \prime}, 5^{\prime \prime}$-tetracarboxylic acid, Fig. 1), were prepared via a mixedligand strategy; the single-crystal structure of $\mathbf{C u}(\mathbf{t p t c})$ was previously reported in 2006. ${ }^{39}$ The structures of the two tetracarboxylic ligands $\left(\mathrm{H}_{4} \mathrm{dbda}\right.$ and $\left.\mathrm{H}_{4} \mathrm{tptc}\right)$ are very similar, both using square-planar 4-connected nodes with the distance between 4 and $4^{\prime}$ carbon atoms in $\mathrm{H}_{4} \mathrm{dbda}$ of $11.57 \AA$ versus $11.38 \AA$ in $\mathrm{H}_{4}$ tptc. The synthesis of $\mathbf{C u}(\mathbf{d b d a})_{\boldsymbol{x}}(\mathbf{t p t c})_{1-\boldsymbol{x}}(x=0.75,0.49,0.18)$ was achieved via a PSE approach using Zn(dbda) $)_{\boldsymbol{x}}(\mathbf{t p t c})_{\mathbf{1}-\boldsymbol{x}}$ MOFs as precursors. Both EDX and ICP-OES results (Table S2 and Fig. S20-S23, ESI $\dagger$ ) showed the metal content of $\mathrm{Cu}$ (II) in all of the $\mathbf{C u}(\mathbf{d b d a})_{\boldsymbol{x}}(\mathbf{t p t c})_{\mathbf{1}-\boldsymbol{x}}(x=0.75,0.49,0.18,0)$ was $>92 \%$, thus indicating near complete PSE. The PXRD patterns of the mixedligand MOFs $\mathbf{C u}(\mathbf{d b d a})_{\boldsymbol{x}}(\mathbf{t p t c})_{\mathbf{1}-\boldsymbol{x}}$ were all in good agreement with calculated patterns (Fig. S24, ESI $\dagger$ ). The ratio of $\mathrm{dbda}^{4-}$ and tptc ${ }^{4-}$ in $\mathbf{C u}(\mathbf{d b d a})_{\boldsymbol{x}}(\mathbf{t p t c})_{\mathbf{1}-\boldsymbol{x}}(x=0.75,0.49,0.18)$ determined by ${ }^{1} \mathrm{H}$ NMR (Fig. S25, ESI $\dagger$ ) were very close to the expected values $(0.75,0.50$, and 0.25 based on the ratio of starting materials). In addition, a direct solvothermal synthesis was examined for the preparation of $\mathbf{C u}(\mathbf{d b d a})_{\boldsymbol{x}}(\mathbf{t p t c})_{\mathbf{1}-\boldsymbol{x}} \cdot{ }^{39}$ However, the loading of $\mathrm{dbda}^{4-}$ through solvothermal methods was much lower than
Table 1 Friedel-Crafts reaction between indole and $\beta$-nitrostyrenes to produce 3-(2-nitro-1-phenylethyl)- $1 \mathrm{H}$-indoles

\begin{tabular}{|c|c|c|c|c|c|}
\hline Entry & $\mathrm{R}^{a}$ & Catalyst & Temp. $\left({ }^{\circ} \mathrm{C}\right)$ & Time (h) & Yield (\%) \\
\hline 1 & $\mathrm{H}$ & None & 50 & 24 & 0 \\
\hline 2 & $\mathrm{H}$ & $\mathrm{H}_{4} \mathrm{dbda}^{a}$ & 50 & 24 & 32 \\
\hline 3 & $\mathrm{H}$ & $\mathrm{Cu}\left(\mathrm{NO}_{3}\right)_{2}{ }^{b}$ & 50 & 24 & 28 \\
\hline 4 & $\mathrm{H}$ & Zn(dbda) & 50 & 24 & 0 \\
\hline 5 & $\mathrm{H}$ & $\mathrm{Cu}(\mathrm{dbda})$ & 25 & 24 & 60 \\
\hline 6 & $\mathrm{H}$ & Cu(dbda) & 35 & 24 & 78 \\
\hline 7 & $\mathrm{H}$ & $\mathrm{Cu}(\mathrm{dbda})$ & 50 & 1 & 60 \\
\hline 8 & $\mathrm{H}$ & $\mathrm{Cu}(\mathrm{dbda})$ & 50 & 8 & 95 \\
\hline 9 & $\mathrm{H}$ & $\mathrm{Cu}(\mathrm{dbda})$ & 50 & 24 & $>99$ \\
\hline 10 & $\mathrm{Cl}$ & $\mathrm{Cu}(\mathrm{dbda})$ & 50 & 24 & 97 \\
\hline 11 & $\mathrm{~F}$ & Cu(dbda) & 50 & 24 & 91 \\
\hline 12 & $\mathrm{Br}$ & Cu(dbda) & 50 & 24 & 92 \\
\hline 13 & $\mathrm{CH}_{3}$ & Cu(dbda) & 50 & 24 & 90 \\
\hline 14 & $\mathrm{OCH}_{3}$ & $\mathrm{Cu}(\mathrm{dbda})$ & 50 & 24 & 74 \\
\hline 15 & $\mathrm{NO}_{2}$ & Cu(dbda) & 50 & 24 & 61 \\
\hline 16 & $\mathrm{H}$ & $\mathrm{Cu}(\mathrm{dbda})_{0.75}(\mathrm{tptc})_{0.25}$ & 50 & 24 & 99 \\
\hline 17 & $\mathrm{H}$ & $\mathrm{Cu}(\mathrm{dbda})_{0.49}(\mathrm{tptc})_{0.51}$ & 50 & 24 & 95 \\
\hline 18 & $\mathrm{H}$ & UiO-67-Squar/bpdc ${ }^{c}$ & 50 & 24 & 95 \\
\hline 19 & $\mathrm{H}$ & UiO-67-Urea/bpdc ${ }^{c}$ & 50 & 24 & 79 \\
\hline 20 & $\mathrm{H}$ & $\mathrm{Cu}(\mathrm{dbda})_{0.18}(\mathrm{tptc})_{0.82}$ & 50 & 24 & 88 \\
\hline 21 & $\mathrm{H}$ & $\mathrm{Cu}(\mathrm{tptc})$ & 50 & 24 & 38 \\
\hline
\end{tabular}

Conditions: indole $(0.15 \mathrm{mmol}), \beta$-nitrostyrenes $(0.10 \mathrm{mmol})$, and catalyst $(5 \mathrm{~mol} \%)$ in $\mathrm{CHCl}_{3}(1 \mathrm{~mL})$. Yields monitored by ${ }^{1} \mathrm{H}$ NMR. See ESI for details. ${ }^{a}$ Catalyst loading was $10 \mathrm{~mol} \%{ }^{b}$ Catalyst loading was $20 \mathrm{~mol} \% .{ }^{c}$ Conditions: indole $(0.02 \mathrm{mmol}), \beta$-nitrostyrene $(0.014 \mathrm{mmol})$, and catalyst $(10 \mathrm{~mol} \%)$ in toluene $(0.7 \mathrm{~mL})$, see ref. 20 for details.

the ratio used in the synthesis, with initial ratios of $\mathrm{dbda}^{4-}$ of 0.50 and 0.25 giving incorporation of only $x=0.31$ and 0.12 , respectively. Moreover, $\mathbf{C u ( d b d a ) ~ c o u l d ~ n o t ~ b e ~ o b t a i n e d ~ u s i n g ~}$ solvothermal methods (Fig. S26 and S27, ESI $\dagger$ ). The permanent porosity of $\mathbf{C u}(\mathbf{d b d a})_{\boldsymbol{x}}(\mathbf{t p t c})_{\mathbf{1}-\boldsymbol{x}}$ were also evaluated by $\mathrm{N}_{2}$ sorption isotherms at $77 \mathrm{~K}$, giving the expected type-I isotherms (Fig. 3). The BET surface areas of $\mathbf{C u}(\mathbf{d b d a})_{\boldsymbol{x}}(\mathbf{t p t c})_{\mathbf{1}-\boldsymbol{x}}(x=0.75,0.49,0.18)$ were $1884 \pm 61 \mathrm{~m}^{2} \mathrm{~g}^{-1}, 1946 \pm 124 \mathrm{~m}^{2} \mathrm{~g}^{-1}$, and $1887 \pm 45 \mathrm{~m}^{2} \mathrm{~g}^{-1}$, respectively, with total pore volumes of $\mathbf{C u}(\mathbf{d b d a})_{\boldsymbol{x}}(\mathbf{t p t c})_{\mathbf{1}-\boldsymbol{x}}$ $(x=0.75,0.49,0.18)$ of $0.775 \mathrm{~cm}^{3} \mathrm{~g}^{-1}, 0.803 \mathrm{~cm}^{3} \mathrm{~g}^{-1}$, and $0.775 \mathrm{~cm}^{3} \mathrm{~g}^{-1}$, respectively. These results show that the porosity of the $\mathbf{C u}(\mathbf{d b d a})_{\boldsymbol{x}}(\mathbf{t p t c})_{\mathbf{1}-\boldsymbol{x}}$ fall in the expected range between those of the single-ligand MOFs, Cu(dbda) $\left(1516 \mathrm{~m}^{2} \mathrm{~g}^{-1}\right)$ and Cu(tptc) (1942 $\left.\mathrm{m}^{2} \mathrm{~g}^{-1}\right)$.

$\mathbf{C u}(\mathbf{d b d a})_{\boldsymbol{x}}(\mathbf{t p t c})_{\mathbf{1}-\boldsymbol{x}}$ was employed as catalyst for the FriedelCrafts reaction between indole $(0.15 \mathrm{mmol})$ and $\beta$-nitrostyrene ( $0.1 \mathrm{mmol})$, carried out at $50{ }^{\circ} \mathrm{C}$ in $\mathrm{CHCl}_{3}$ for $24 \mathrm{~h}(5 \mathrm{~mol} \%$ loading, based on the empirical formula $\mathrm{Cu}_{4}(\mathrm{dbda})_{2 x}(\mathrm{tptc})_{2-2 x}\left(\mathrm{H}_{2} \mathrm{O}\right)_{4}$, $x=0.75,0.49,0.18$ ). Using Cu(tptc) (5 mol\% loading, no squaramide sites) as a catalyst gave a low yield of $\sim 39 \%$ (Fig. S28, ESI $\dagger$ ); the residual activity may arise from the Lewis acid $\mathrm{Cu}$ (II) sites, as $\mathrm{Cu}(\mathrm{II})$-complexes have been reported to show catalytic activity for the Friedel-Crafts reaction. ${ }^{40}$ Consistent with this observation, $\mathrm{Cu}\left(\mathrm{NO}_{3}\right)_{2}$, gave a $28 \%$ conversion under the same reaction conditions. In contrast, for $\mathbf{C u}(\mathbf{d b d a})_{\boldsymbol{x}}(\mathbf{t p t c})_{\mathbf{1}-\boldsymbol{x}}$ $(x=1,0.75,0.49,0.18,0)$, activity increased with increasing dbda $^{4-}$ content: $39 \%$ (Cu(tptc)), 88\% (Cu(dbda) $)_{\mathbf{0 . 1 8}}(\mathbf{t p t c})_{\mathbf{0 . 8 2}}$ ),

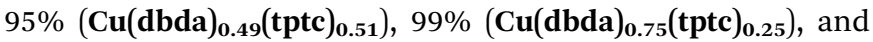
$>99 \%$ (Cu(dbda)), respectively. These results verify that the squaramide group is the governing catalytic functional group 
in these MOFs. For a more direct comparison to the prior reports, ${ }^{20}$ a $2.45 \mathrm{~mol} \%$ loading of catalyst $\mathbf{C u}(\mathbf{d b d a})_{\mathbf{0 . 4 9}}(\mathbf{t p t c})_{\mathbf{0 . 5 1}}$ achieved the same catalytic performance as the reported UiO-67-Squar/bpdc at $10 \mathrm{~mol} \%$ loading ( $95 \%$ yield at $50{ }^{\circ} \mathrm{C}$ for $24 \mathrm{~h}$ ). ${ }^{20}$ The result further verified the high activity of the $\mathrm{dbda}^{4-}$-based MOF.

Taken together, $\mathbf{C u}$ (dbda) has features that compliment and distinguish it from the previously reported UiO-67-Squar/bpdc catalyst. $^{20} \mathbf{C u}$ (dbda) has a different MOF structure type from UiO-67-Squar/bpdc, wherein the catalytic group is part of the ligand 'backbone' rather than a dangling component. Depending on catalyst design, one can envision scenarios where one or the other functional group arrangement might be preferable. Also, in contrast to UiO-67-Squar/bpdc, Cu(dbda) allows for 100\% functional ligand incorporation without loss of surface area. Indeed, using $\mathrm{H}_{4}$ tptc as a complimentary, unfunctionalized ligand the $\mathbf{C u}(\mathbf{d b d a})$ system is not limited with respect to the amount of squaramide ligand that can be included while maintaining a high degree of porosity and activity. Both $\mathbf{C u}(\mathbf{d b d a})_{\boldsymbol{x}}(\mathbf{t p t c})_{\mathbf{1}-\boldsymbol{x}}$ and UiO-67-Squar/bpdc catalysts show good activity under similar conditions, and hence each helps advance the ability of utilizing squaramides in MOF-based catalytic systems.

In summary, we prepared a squaramide tetracarboxylate ligand, and developed catalytic squaramide MOFs prepared via metal PSE from $\mathrm{Zn}$ (II) precursor MOFs. The Cu(II) MOFs were more stable and hence showed good catalytic performance when compared to the unstable parent $\mathrm{Zn}$ (II) MOF, in a Friedel-Crafts reaction of indole with $\beta$-nitrostyrenes. A series of isostructural MOFs Cu(dbda) $)_{x}(\mathbf{t p t c})_{1-x}(x=0.75,0.49,0.18,0)$ showed that the catalytic performance of these MOFs increased with increasing amounts of the squaramide ligand, demonstrating that squaramide MOFs are promising MOF-supported heterogeneous organocatalysts. Our ongoing progress with squaramide MOFs are focusing on their applications in molecular recognition and ion sensing.

This work was financially supported by a grant from the Division of Chemistry of the National Science Foundation (CHE-1359906) and China Scholarship Council.

\section{Notes and references}

1 S. J. Connon, Chem. - Eur. J., 2006, 12, 5418-5427.

2 J. Aleman, A. Parra, H. Jiang and K. A. Jorgensen, Chem. - Eur. J., 2011, 17, 6890-6899.

3 R. I. Storer, C. Aciro and L. H. Jones, Chem. Soc. Rev., 2011, 40, 2330-2346.

4 J. P. Malerich, K. Hagihara and V. H. Rawal, J. Am. Chem. Soc., 2008, 130, 14416-14417.

5 D. Roca-Lopez, U. Uria, E. Reyes, L. Carrillo, K. A. Jorgensen, J. L. Vicario and P. Merino, Chem. - Eur. J., 2016, 22, 884-889.

6 Y. Wang, J. Pan, R. Jiang, Y. Wang and Z. Zhou, Adv. Synth. Catal., 2016, 358, 195-200.

7 H. Zhang, S. Lin and E. N. Jacobsen, J. Am. Chem. Soc., 2014, 136, 16485-16488.
8 C. H. Cheon and H. Yamamoto, Tetrahedron Lett., 2009, 50, 3555-3558.

9 P. Chauhan, S. Mahajan, U. Kaya, D. Hack and D. Enders, Adv. Synth. Catal., 2015, 357, 253-281.

10 Y. Zhu, J. P. Malerich and V. H. Rawal, Angew. Chem., Int. Ed., 2010, 49, 153-156.

11 H. Jiang, M. W. Paixao, D. Monge and K. A. Jorgensen, J. Am. Chem. Soc., 2010, 132, 2775-2783.

12 B. Soberats, L. Martinez, E. Sanna, A. Sampedro, C. Rotger and A. Costa, Chem. - Eur. J., 2012, 18, 7533-7542.

$13 \mathrm{X}$. Wu, N. Busschaert, N. J. Wells, Y. B. Jiang and P. A. Gale, J. Am. Chem. Soc., 2015, 137, 1476-1484.

14 C. Gaeta, C. Talotta, P. Della Sala, L. Margarucci, A. Casapullo and P. Neri, J. Org. Chem., 2014, 79, 3704-3708.

15 B. Shan, Y. Liu, R. Shi, S. Jin, L. Li, S. Chen and Q. Shu, RSC Adv., 2015, 5, 96665-96669.

16 A. Rostami, C. J. Wei, G. Guerin and M. S. Taylor, Angew. Chem., Int. $E d ., 2011,50,2059-2062$.

17 D. Quiñonero, R. Prohens, C. Garau, A. Frontera, P. Ballester, A. Costa and P. M. Deyà, Chem. Phys. Lett., 2002, 351, 115-120.

18 A. Portell, R. Barbas, D. Braga, M. Polito, C. Puigjaner and R. Prohens, CrystEngComm, 2009, 11, 52-54.

19 J. V. Alegre-Requena, E. Marqués-López, R. P. Herrera and D. D. Díaz, CrystEngComm, 2016, 18, 3985-3995.

20 C. M. McGuirk, M. J. Katz, C. L. Stern, A. A. Sarjeant, J. T. Hupp, O. K. Farha and C. A. Mirkin, J. Am. Chem. Soc., 2015, 137, 919-925.

21 L. Du, Z. Lu, K. Zheng, J. Wang, X. Zheng, Y. Pan, X. You and J. Bai, J. Am. Chem. Soc., 2013, 135, 562-565.

22 J. A. Mason, J. Oktawiec, M. K. Taylor, M. R. Hudson, J. Rodriguez, J. E. Bachman, M. I. Gonzalez, A. Cervellino, A. Guagliardi, C. M. Brown, P. L. Llewellyn, N. Masciocchi and J. R. Long, Nature, 2015, 527, 357-361.

23 B. Chen, S. Xiang and G. Qian, Acc. Chem. Res., 2010, 43, 1115-1124.

24 N. T. Nguyen, H. Furukawa, F. Gandara, C. A. Trickett, H. M. Jeong, K. E. Cordova and O. M. Yaghi, J. Am. Chem. Soc., 2015, 137, 15394-15397.

25 M. H. Beyzavi, R. C. Klet, S. Tussupbayev, J. Borycz, N. A. Vermeulen, C. J. Cramer, J. F. Stoddart, J. T. Hupp and O. K. Farha, J. Am. Chem. Soc., 2014, 136, 15861-15864.

26 J. Liu, L. Chen, H. Cui, J. Zhang, L. Zhang and C. Y. Su, Chem. Soc. Rev., 2014, 43, 6011-6061.

27 T. Sawano, N. C. Thacker, Z. Lin, A. R. McIsaac and W. Lin, J. Am. Chem. Soc., 2015, 137, 12241-12248.

28 A. H. Chughtai, N. Ahmad, H. A. Younus, A. Laypkov and F. Verpoort, Chem. Soc. Rev., 2015, 44, 6804-6849.

29 S. M. Cohen, Chem. Rev., 2012, 112, 970-1000.

30 N. T. S. Phan, K. K. A. Le and T. D. Phan, Appl. Catal., A, 2010, 382, 246-253.

31 K.-I. Shimizu, K. Niimi and A. Satsuma, Appl. Catal., A, 2008, 349, 1-5.

32 T. B. Poulsen and K. A. Jørgensen, Chem. Rev., 2008, 108, 2903-2915.

33 G. Dessole, R. P. Herrera and A. Ricci, Synlett, 2004, 2374-2378.

34 E. A. Hall, L. R. Redfern, M. H. Wang and K. A. Scheidt, ACS Catal., 2016, 6, 3248-3252.

35 A. Rostami, A. Colin, X. Y. Li, M. G. Chudzinski, A. J. Lough and M. S. Taylor, J. Org. Chem., 2010, 75, 3983-3992.

36 M. Bosch, M. Zhang and H.-C. Zhou, Adv. Chem., 2014, 2014, 1-8.

37 Z. Wei, W. Lu, H.-L. Jiang and H.-C. Zhou, Inorg. Chem., 2013, 52, 1164-1166.

38 K. S. W. Sing, D. H. Everett, R. A. W. Haul, L. Moscou, R. A. Pierotti, J. Rouquerol and T. Siemieniewska, Pure Appl. Chem., 1985, 57, 603-609.

39 X. Lin, J. Jia, X. Zhao, K. M. Thomas, A. J. Blake, G. S. Walker, N. R. Champness, P. Hubberstey and M. Schroder, Angew. Chem., Int. Ed., 2006, 45, 7358-7364.

40 W. Li, Catal. Lett., 2014, 144, 943-948. 